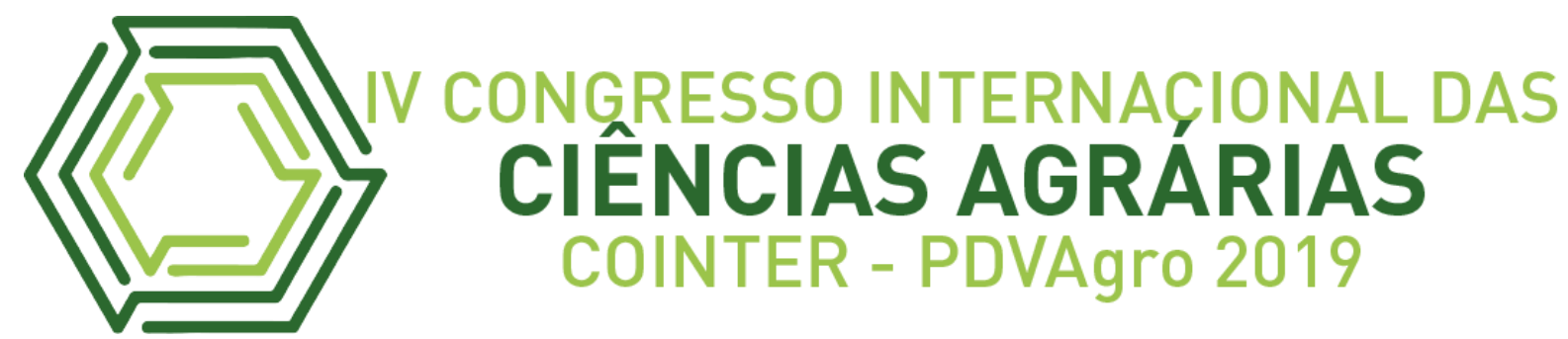

\title{
A FAVA COMO BIOCATALISADOR EM REAÇÕES DE BIORREDUÇÃO DE COMPOSTOS CARBONÍLICOS
}

\section{FAVA COMO BIOCATALIZADOR EN REACCIONES BIOLÓGICAS DE COMPUESTOS CARBONILICOS}

\section{FAVA AS A BIOCATALIZER IN BIOLOGICAL REACTIONS OF CARBONILIC COMPOUNDS}

\author{
Apresentação: Comunicação Oral \\ Daniel Yuri Xavier de Sousa ${ }^{1}$; Antonia Flávia Costa Souto $^{2}$; Lizienny Pinheiro Peixoto ${ }^{3}$ Isis \\ Alves Palmeira ${ }^{4}$; Allana Kellen Lima Santos Pereira ${ }^{5}$
}

\section{DOI: https://doi.org/10.31692/2526-7701.IVCOINTERPDVAgro.2019.0084}

\begin{abstract}
Resumo
Existe na literatura uma grande quantidade de vegetais utilizados em processos biocatalíticos como fonte de enzimas (Biocatalizadores). A indústria almeja uma grande parte dessas enzimas, pois tem forte interesse nas reações de bioredução de compostos carbonilados (Biocatálise), especificamente para produção de fármacos, cosméticos e agroquímicos. O trabalho em questão tem como objetivo geral estudar o potencial biocatalítico das fabaceas, para a biorredução de diferentes substratos carbonílicos. A metodologia consiste na biorredução de cetonas aromáticas e alifáticas partir de redutases presentes em células íntegras da espécie vegetal, feijão-fava (Phaseolus lunatus L), para a biorredução de diferentes substratos carbonílicos, a fim de obtermos seus álcoois correspondentes. Os produtos foram purificados em cromatografia em coluna e identificados através de cromatografia em camada delgada (CCD) e espectroscopia no infravermelho (IV), A quantificação encontra-se em processo de análise. Os excessos enantioméricos (\% ee) dos produtos quirais serão determinados através de Cromatógrafo Gasoso (CG-DIC) e CLAE utilizando coluna quiral. Foi realizada a extração do concentrado enzimático da fava e determinado o teor de proteínas neste. Para essa determinação foram utilizados dois métodos rotineiros de laboratórios: o Método de Lowry, modificado por Hartree (HARTREE, 1972) e o Método de Bradford (BRADFORD, 1976). A partir dos resultados obtidos chegamos à conclusão que ocorreram as biotransformações esperadas.
\end{abstract}

Palavras-Chave: Biocatálise, fava, compostos carbonilados e enzimas.

\footnotetext{
${ }^{1}$ Agronomia, Universidade Federal do Cariri, yuri.xavier@aluno.ufca.edu.br

${ }^{2}$ Agronomia, Universidade Federal do Cariri, flaviasouto15@gmail.com

${ }^{3}$ Engenharia de Materiais, Universidade Federal do Cariri, lizienny.peixoto@aluno.ufca.edu.br

${ }^{4}$ Agronomia, Universidade Federal do Cariri, isis.palmeira@aluno.ufca.edu.br

${ }^{5}$ Doutora, Universidade Federal do Cariri, allana.lima@ufca.edu.br
} 


\title{
Resumen
}

Hay una gran cantidad de vegetales utilizados en procesos biocatalíticos como fuente de enzimas (biocatalizadores). La industria apunta a una gran parte de estas enzimas, ya que tiene un gran interés en las reacciones de bioreducción de compuestos carbonilados (Biocatálisis), específicamente para la producción de productos farmacéuticos, cosméticos y agroquímicos. El presente trabajo tiene como objetivo general estudiar el potencial biocatalítico de las fabaceas, para la bioreducción de diferentes sustratos de carbonilo. La metodología consiste en la bioreducción de cetonas aromáticas y alifáticas a partir de reductasas presentes en células enteras de la especie vegetal, fava (Phaseolus lunatus L), para la bioreducción de diferentes sustratos carbónicos, con el fin de obtener sus correspondientes alcoholes. Los productos se purificaron por cromatografía en columna y se identificaron por cromatografía en capa fina (CCD) y espectroscopía infrarroja (IR). La cuantificación está bajo análisis. Los excesos enantioméricos (\% ee) de productos quirales se determinarán mediante cromatografía de gases (CG-DIC) y HPLC usando una columna quiral. El concentrado enzimático se extrajo del frijol y se determinó el contenido de proteína. Para esta determinación, se utilizaron dos métodos de laboratorio de rutina: el Método Lowry modificado por Hartree (HARTREE, 1972) y el Método Bradford (BRADFORD, 1976). De los resultados obtenidos llegamos a la conclusión de que ocurrieron las biotransformaciones esperadas.

Palabras Clave: Biocatálisis, frijol, compuestos de carbonilo y enzimas.

\begin{abstract}
There is a large amount of vegetables used in biocatalytic processes as a source of enzymes (Biocatalysts). The industry targets a large part of these enzymes, as it has a strong interest in bioreduction reactions of carbonylated compounds (Biocatalysis), specifically for the production of pharmaceuticals, cosmetics and agrochemicals. The present work has as general objective to study the biocatalytic potential of the fabaceas, for the bioreduction of different carbonyl substrates. The methodology consists in the bioreduction of aromatic and aliphatic ketones from reductases present in whole cells of the plant species, fava bean (Phaseolus lunatus L), for the bioreduction of different carbonic substrates, in order to obtain their corresponding alcohols. The products were purified by column chromatography and identified by thin layer chromatography (CCD) and infrared (IR) spectroscopy. Quantitation is under analysis. Enantiomeric excesses (\% ee) of chiral products will be determined by Gas Chromatograph (CG-DIC) and HPLC using chiral column. The enzyme concentrate was extracted from the bean and the protein content was determined. For this determination, two routine laboratory methods were used: the Hartree-modified Lowry Method (HARTREE, 1972) and the Bradford Method (BRADFORD, 1976). From the obtained results we came to the conclusion that the expected biotransformations occurred.
\end{abstract}

Keywords: Biocatalysis, bean, carbonylated compounds and enzymes. 


\section{Introdução}

Como um processo eficiente para a síntese de compostos orgânicos quirais surgiram as biotransformações e podem ser definidas como modificações da estrutura molecular de uma substância catalisada por meio biológico (MACHADO, et al 2009). A grande procura por essas substâncias, é pelo simples fato do seu potencial biotecnológico (ANDRADE et al, 2006).

Os catalisadores biológicos têm em suas composições características que os distinguem dos catalisadores convencionais, e ainda apresentam características da química verde. A fim de se reduzir a utilização de matérias-primas de origem fóssil, a busca por produtos naturais vem aumentando continuamente (OMORI, PORTAS, DE OLIVEIRA 2012). As reações biocatalíticas podem ser aplicadas na fitoterapia de poluentes orgânicos (ANDRADE et al., 2006), lactonização enzimática (ORDEN et al., 2009; ANDRADE et al., 2006), hidrólise de ésteres (ORDEN et al., 2009; BIZERRA et al., 2010) além de hidroxilação (ISHIHARA et al., 2003) e a glicosilação (GIRI et al., 2001).

As pesquisas nas áreas de biocatálise crescem a cada dia, é seu trunfo é extremamente útil para a produção de novos materiais, e no melhoramento de processos, pois a fabricação de produtos enantiosseletivos, regioespecíficos, obtidos de forma límpida podem ser aplicados em diversos campos da ciência, em conotação a indústria (MORAES, 2014). A demanda por materiais de origem fóssil e com alto poder contaminante, e com uma meia-vida de valor alto, preocupa não só os pesquisadores, mas também o meio ambiente, por isso a busca de novas metodologias "verde" é importantíssimas (LIMA, ANGNES, 1999).

O estudo inicia-se com as biotransformações em compostos carbonílicos (substratos) tais como aldeídos e cetonas aromáticos e alifáticos utilizando as células íntegras de espécies vegetais, com ênfase nas da família Fabaceae. O trabalho se estabelece atrelado ao desenvolvimento de uma nova linha de pesquisa na Universidade Federal do Cariri: A biocatálise, já está sendo utilizada por uma série de instituições de ensino superior e está lhes gratificando com inúmeras teses e publicações, norteando assim o sucesso. Trazendo consigo o aspecto de química limpa e de fácil utilização, é proposto o desenvolvimento científico no estado do Ceará, em maior especificidade a região do Cariri na intuição de criar-se um novo ramo de pesquisa visando o crescimento dessa localidade. 
Como objetivo geral temos a contribuição para o conhecimento da diversidade biológica vegetal, explorando a nível moleculares fontes naturais vegetais, buscando implantar a biocatálise como uma nova linha de pesquisa de produtos naturais na Universidade Federal do Cariri, contribuindo assim para o crescimento científico na região do Cariri. Em caráter específico: realizar biotransformações, especificamente biorreduções, em substratos carbonílicos como cetonas e aldeídos aromáticos e alifáticos utilizando células íntegras de espécies vegetais, em especial as da família Fabaceae; obter e determinar os padrões; determinar as estruturas dos produtos das biotransformações; obter os extratos enzimáticos; quantificar o teor de proteínas; determinar os excessos enantioméricos e da enantiosseletividade e participar de eventos científicos e publicar em revistas científicas especializadas.

\section{Fundamentação Teórica}

A origem da biocatálise é desde primórdios de nossa civilização quando povos primitivos utilizavam culturas mistas de microrganismos, na fabricação de pães, de bebidas alcoólicas e de derivados do leite em processos fermentativos. Estudos científicos das bioconversões foram impulsionados por químicos e bioquímicos desde século XIX. O primeiro registro na literatura de redução microbiológica de uma molécula orgânica foi com a redução do furfural a álcool furfurílico em condições anaeróbica de fermentação (VIEIRA et al, 1996).

As enzimas possuem capacidades de realizar reações de oxidação, redução, hidroxilação, metilação, acetilação, isomerização, glicosilação e esterificação. Grupos de enzimas como as desidrogenases, oxigenases e oxidases são utilizadas em reações de oxirredução de compostos carbonílicos como aldeídos e cetonas, e de dupla ligação $\mathrm{C}=\mathrm{C}$. A redução de cetonas assimétricas é uma das mais importantes reações para produção de álcoois quirais não racêmicos, os quais são de grande importância para a indústria, principalmente na síntese de produtos farmacêuticos e agroquímicos (CONTI, 2001)

\section{Metodologia}

O biocatalisador utilizado para a realização das biorreduções foi o feijão-fava (Phaseolus lunatus) comprado no mercado do Pirajá no município de Juazeiro do Norte. 
Os padrões dos álcoois racêmicos foram obtidos através de síntese química a partir das cetonas e dos aldeídos padrões com borohidreto de sódio. Em erlenmeyeres de $250 \mathrm{ml}$ adicionou-se respectivamente, $1 \mathrm{~g}$ de cada substrato e $50 \mathrm{ml}$ de etanol. A solução resultante foi colocada em um banho de gelo e agitada, utilizando um agitador magnético. Agitando-se o erlenmeyer constantemente, $200 \mathrm{mg}$ de borohidreto de sódio foi adicionado em pequenas porções usando-se uma espátula. Após adição, o sistema foi deixado em agitação por cinco horas. Com o fim da reação, adicionou-se lentamente $\mathrm{HCl} 0,1 \mathrm{M}(20 \mathrm{ml})$ até cessar o desprendimento de hidrogênio, seguido de mais $50 \mathrm{ml}$ de água . A purificação dos produtos foi efetuada através de coluna cromatográfica de sílica gel. Todos os padrões foram analisados por infravermelho.

A metodologia a ser empregada foi aquela desenvolvida por Machado (2006). Nos experimentos foram utilizadas as sementes da espécie vegetal, feijão-fava, como biocatalisador, em solução aquosa, juntamente com os substratos a serem testados e agitados em Shake (150 rpm). A biorredução de cetonas e aldeídos aromáticos e alifáticos foram realizadas usando a proporção de $145 \mathrm{ml}$ de água, $200 \mathrm{mg}$ de substrato, acondicionada em Erlenmeyer $(250 \mathrm{ml})$, e submetidas a agitação em Shaker $(150 \mathrm{rpm})$ por um período de $72 \mathrm{~h}$. As amostras então foram filtradas a vácuo e o filtrado foi extraído com AcOEt (3x100mL). As fases orgânicas foram secas com $\mathrm{Na}_{2} \mathrm{SO}_{4}$ anidro e concentradas sob pressão reduzidas. As frações obtidas foram analisadas inicialmente por CCD, recromatografadas em gel de sílica e analisadas por infravermelho (IV), cromatografia gasosa acoplada a espectrometria de massas (CG/EM).

A determinação estrutural dos produtos de biotransformações foi realizada através da análise dos dados espectroscópicos obtidos nas análises por IV, EM e/ou CLAE. As descrições dos modelos e condições dos aparelhos utilizados para caracterização das substâncias encontram-se a seguir:

Os espectros de absorção na região do infravermelho foram registrados em espectrômetro Perkin-Elmer modelo 720. Para as substâncias sólidas foram utilizadas pastilhas de $\mathrm{KBr}$ e para as demais foram preparados filmes.

O cromatógrafo utilizado foi um Cromatógrafo a Gás acoplado à Espectroscopia de Massa (CG-EM) da série QP2010 equipado com coluna capilar de sílica fundida Rtx-5MS (30 $\mathrm{m} \times 0.25 \mathrm{~mm}$ I.D.; $0.25 \mathrm{~m}$ espessura do filme), gás transportador hélio (He) e temperatura programada. Com impacto eletrônico a $70 \mathrm{eV}$ foi usado para analisar os produtos obtidos das 
reações de biorredução e redução com $\mathrm{NaBH}_{4}$. O volume de injeção foi de $1 \mu \mathrm{L}$, utilizando split na razão 1/5. O gás de arraste foi o hélio com fluxo de $1,0 \mathrm{ml} / \mathrm{min}$. A coluna utilizada para análises foi a HP-5MS $(30 \mathrm{~m} \times 25 \mu \mathrm{m})$. A temperatura do injetor foi de $250^{\circ} \mathrm{C}$ e a temperatura inicial da corrida foi de $50^{\circ} \mathrm{C}$, durante $1 \mathrm{~min}$, incrementando $5^{\circ} \mathrm{C} / \mathrm{min}$ até alcançar a temperatura de $200^{\circ} \mathrm{C}$, mantendo-se por mais 4 min e com o tempo total de corrida de 35 min. Os espectros foram comparados com a biblioteca de espectros, NIST 2011.

O método de Bradford utiliza o corante "Coomassie Brilliant Blue" G-250 para a determinação de proteínas totais do biocatalisador, Phaseolus lunatus L.(feijão-fava). Este método é baseado na interação entre o corante GB-250 e macromoléculas de proteínas que contém aminoácidos de cadeias laterais básicas ou aromáticas. No pH de reação, a interação entre a proteína de alto peso molecular e o corante GB-250 provoca o deslocamento do equilíbrio do corante para a forma aniônica, que absorve fortemente em $595 \mathrm{~nm}$ (ZAIA, ZAIA, LICHTIG; 1998)

\section{Resultados e Discussão}

As biorreduções foram realizadas a $30^{\circ} \mathrm{C}$ durante 72 horas, para avaliar o potencial redutor das enzimas presentes nos biocatalisadores. Os bioprodutos encontram-se em análise tanto por IV quanto por GC/MS.

As biotransformações, especificamente as biorreduções, descrevem um sistema de redução economicamente viável e ambientalmente correto. Diferentes metodologias têm sido desenvolvidas no sentido de sintetizar álcoois. A redução estereosseletiva está sendo um dos métodos mais empregados, uma vez que permite a produção desses derivados em rendimentos quantitativos (BIZERRA et al., 2010). A Figura 01 apresenta o esquema das biotransformações dos substratos (padrões) utilizados aos seus respectivos álcoois.

Figura 01: Esquema das biorreduções dos substratos aos seus respectivos álcoois

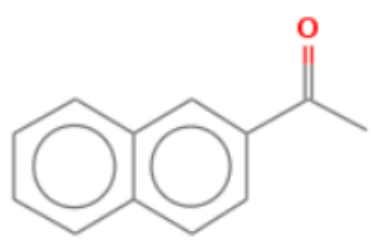

1

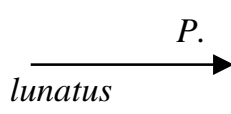

lunatus<smiles>C[C@H](O)c1cccc2ccccc12</smiles>

1A 


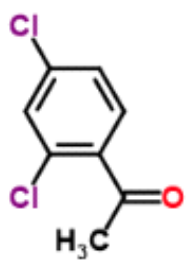

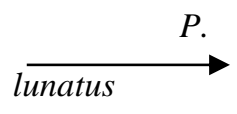

$P$.

lunatus

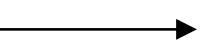

3

Fonte: Própria (2019)<smiles>O=C1CCCc2ccccc21</smiles>

4

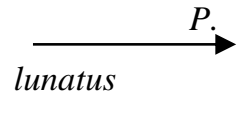<smiles>OC1CCCc2ccccc21</smiles>

$4^{\mathrm{a}}$

Fonte: Própria (2019)

\section{$\underline{\text { Redução dos substratos com } \mathrm{NaBH}_{4}}$}

A síntese química dos álcoois padrões foi realizada com $\mathrm{NaBH}_{4}$, um reagente quimiosseletivo empregado na redução de grupos carbonila. Este é um agente redutor brando que reage rapidamente com aldeídos e cetonas. Através da análise por cromatografia em camada delgada (CCD) e infravermelho (IV) constatamos que a reação aconteceu.

\section{2,4-dicloroacetofenona}

Para acompanhamento das reações de redução foram realizadas CCDs tendo como eluente hexano: acetato $(8 \mathrm{v}: 2 \mathrm{v})$ e reveladas em solução de vanilina, onde pode-se observar os materiais de partida, substrato $(\mathrm{S})$; produtos da reação com $\mathrm{NaBH}_{4}(\mathrm{P})$ e os produtos da reações biocatalíticas (B). A partir dessa análise pode-se constatar, se houve a reação esperada, Figura 02. 
Figura 02: Cromatografia em Camada Delgada de gel de sílica da 2,4-dicloroacetofenona com Phaseolus lunatus L onde temos substrato (S), o produto de síntese convencional (P) e o bioproduto (B).

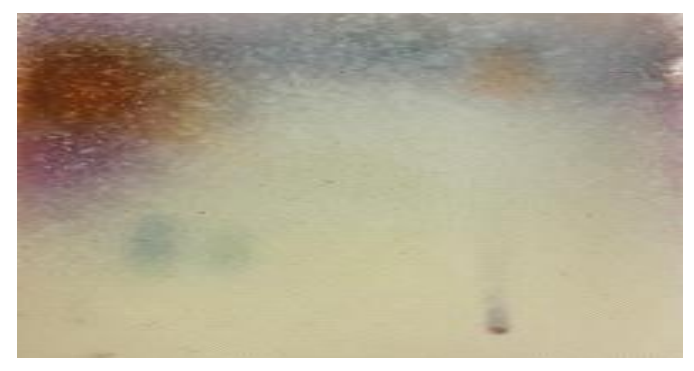

$\mathrm{S} \quad \mathrm{P} \quad \mathrm{B}$

Fonte: Própria (2019)

As análises no infravermelho comprovam que ocorreu a biorredução do composto carbonilíco ao álcool correspondente. As Figuras 03-04 representam os espectros de IV obtidos para o composto 2 (2,4-dicloroacetofenona) e seu bioproduto de biorredução. A partir da análise do espectro de infravermelho os compostos puderam ser caracterizados. No espectro IV do substrato 2 (Figura 03) verificamos a presença de banda de carbonila de cetona conjugada em $1.697 \mathrm{~cm}^{-1}$. Na Figura 04, espectro do bioproduto, constatamos que houve reação de biorredução, pois observamos uma banda em $3.348 \mathrm{~cm}^{-1}$ correspondente à hidroxila de álcool, o que nos sugere a formação do álcool 1-(2,4-diclorofenil)etanol. Porém a reação não ocorreu totalmente, uma vez que verificamos no espectro do bioproduto a presença de banda em $1.691 \mathrm{~cm}^{-1}$ de carbonila de cetona conjugada.

Figura 03: Espectro de infravermelho do substrato 2 (2,4-dicloroacetofenona)

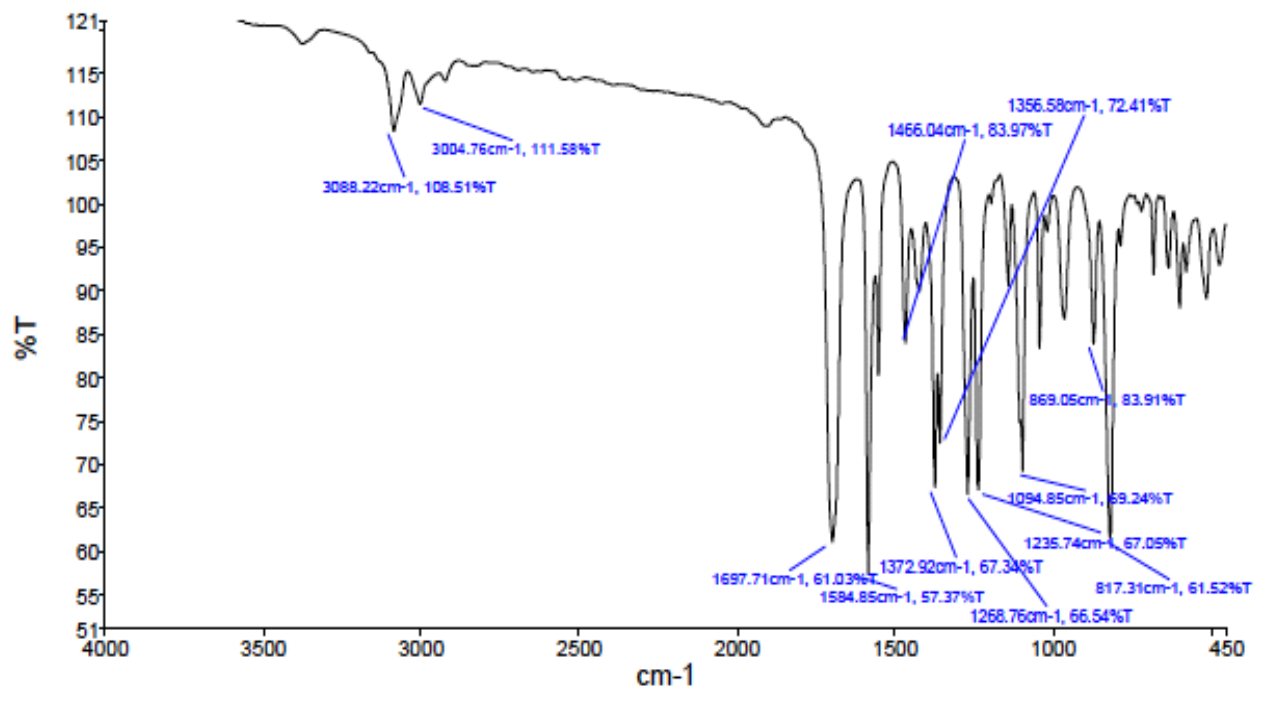


Fonte: espectroscopia no infravermelho - o(s) autor(es)

Figura 04: Espectro do bioproduto de biorredução da 2,4-dicloroacetofenona, álcool 1-(2,4-diclorofenil)etanol

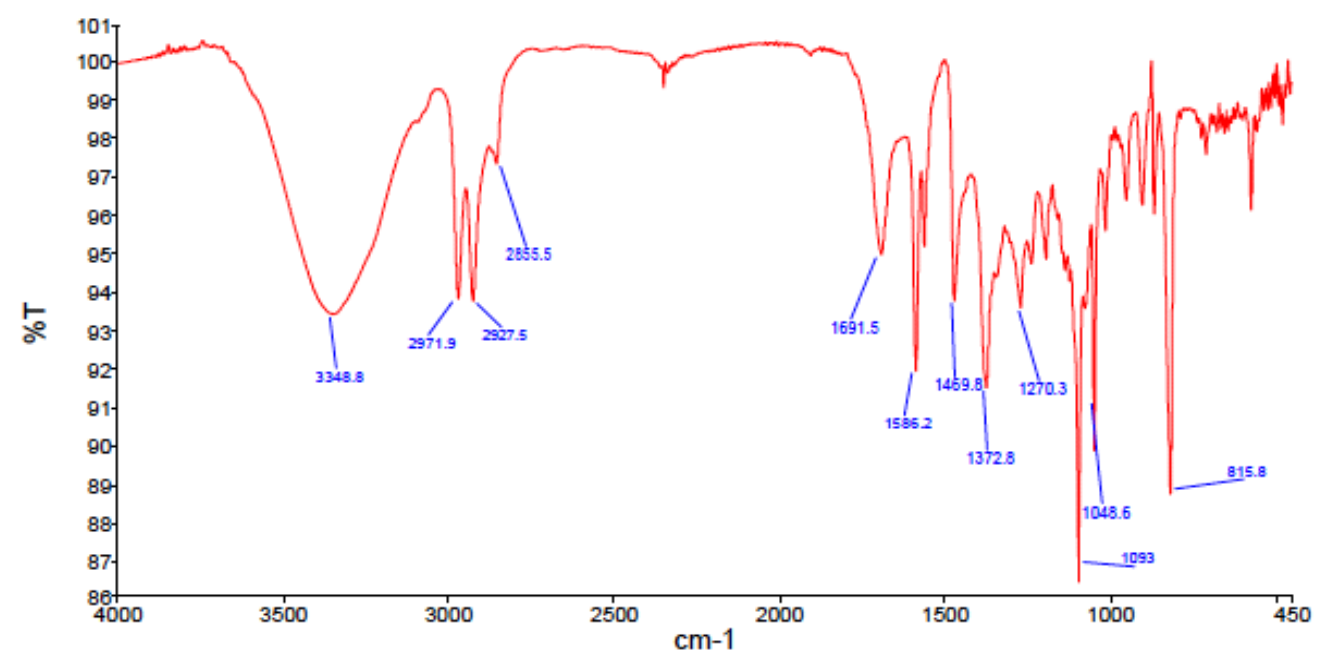

Fonte: espectroscopia no infravermelho - o(s) autor(es)

\section{$\underline{\text { 2-octanona }}$}

Para acompanhamento das reações de redução foram realizadas CCDs tendo como eluente hexano:acetato $(8 \mathrm{v}: 2 \mathrm{v})$ e reveladas em solução de vanilina. A CCD apresentou-se inconclusiva, por esse motivo não há uma imagem da mesma.

As análises no infravermelho comprovam que ocorreu a biorredução do composto carbonilíco ao álcool correspondente. As Figuras 05-06 representam os espectros de IV obtidos para o composto 3 (2-octanona) e seu bioproduto de biorredução. A partir da análise do espectro de infravermelho os compostos puderam ser caracterizados. No espectro IV do substrato 3 (Figura 05) verificamos a presença de banda de carbonila de cetona em $1.717 \mathrm{~cm}^{-}$ 1. Na Figura 06, espectro do bioproduto, constatamos que houve reação de biorredução, pois observamos uma banda em $3.228 \mathrm{~cm}^{-1}$ correspondente à hidroxila de álcool, o que nos sugere a formação do álcool 2-octanol. Porém a reação não ocorreu totalmente, uma vez que verificamos no espectro do bioproduto a presença de banda em $1.709 \mathrm{~cm}^{-1}$ de carbonila de cetona.

Figura 05: Espectro de infravermelho do substrato 3 (2-octanona) 


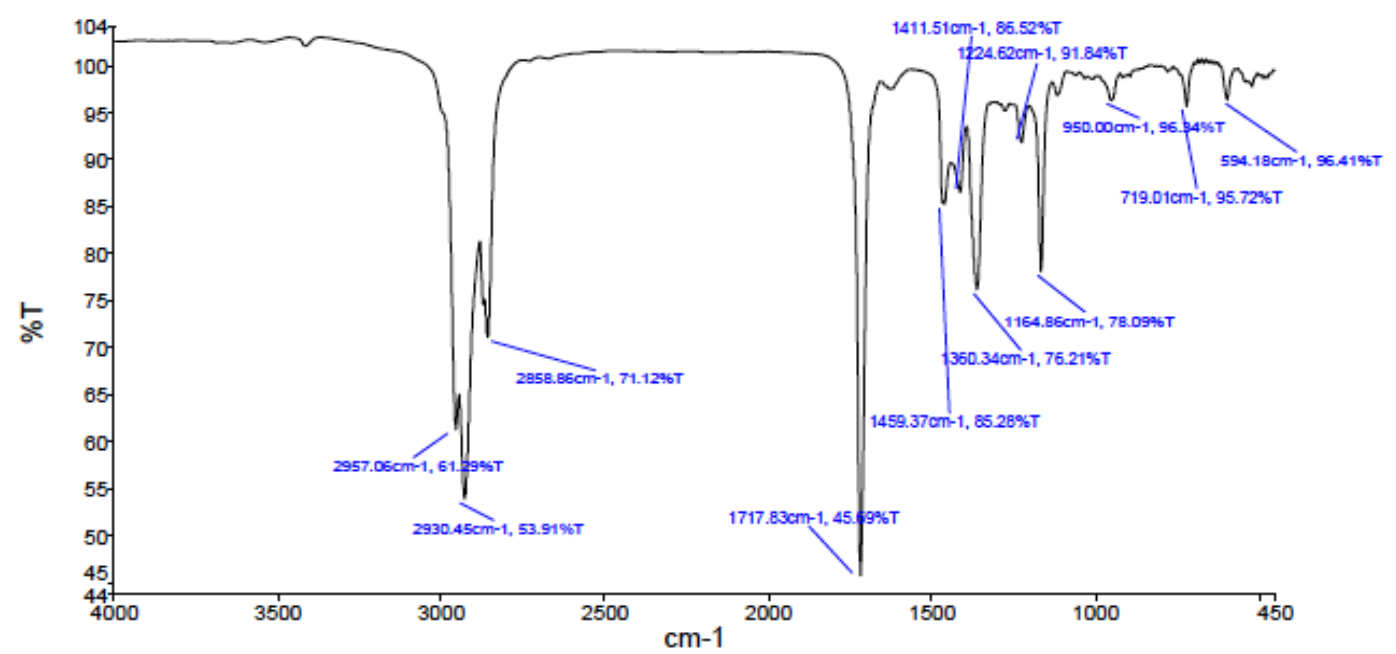

Fonte: espectroscopia no infravermelho - o(s) autor(es)

Figura 06: Espectro do bioproduto de biorredução da 2-octanona, álcool 2-octanol

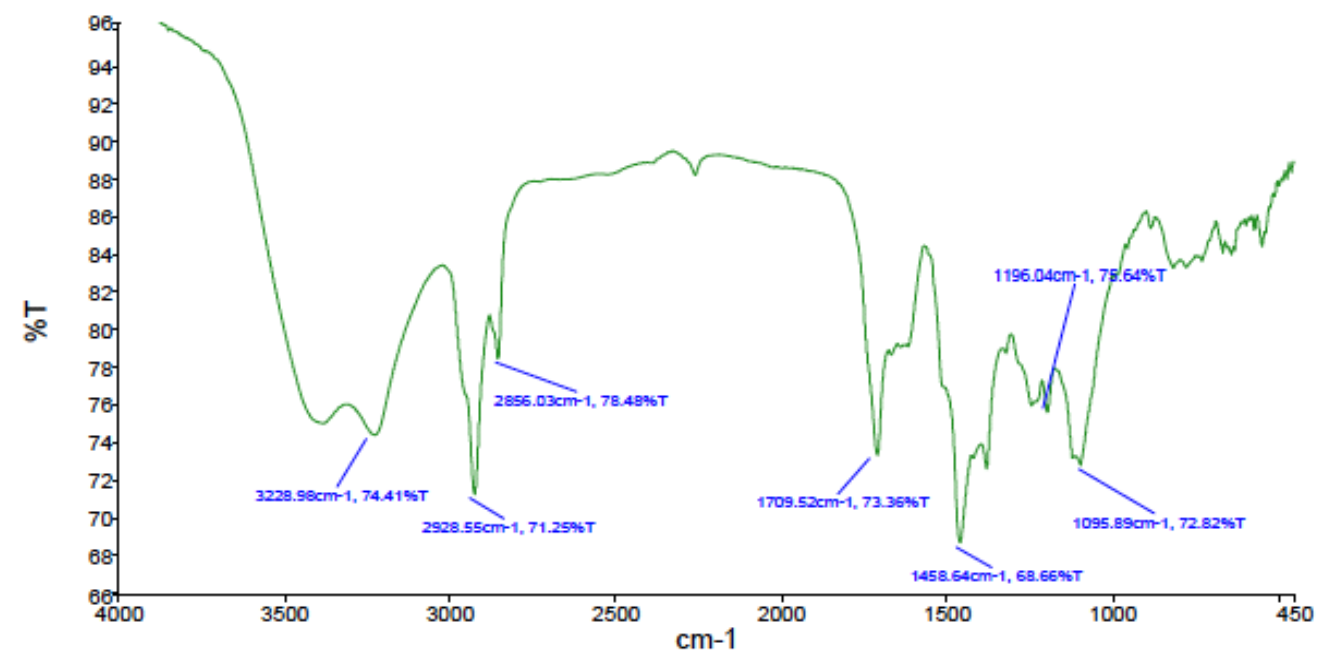

Fonte: espectroscopia no infravermelho - o(s) autor(es)

\section{$\underline{\alpha-t e t r a l o n a}$}

Para acompanhamento das reações de redução foram realizadas CCDs tendo como eluente hexano:acetato $(8 \mathrm{v}: 2 \mathrm{v})$ e reveladas em solução de vanilina, onde pode-se observar os materiais de partida, substrato $(\mathrm{S})$; produtos da reação com $\mathrm{NaBH}_{4}(\mathrm{P})$ e os produtos da reações biocatalíticas (B). A partir dessa análise pode-se constatar, se houve a reação esperada, Figura 07. 
Figura 07: Cromatografia em Camada Delgada de gel de sílica da $\alpha$-tetralona com Phaseolus lunatus L onde temos substrato $(\mathrm{S})$, o produto de síntese convencional $(\mathrm{P})$ e o bioproduto $(\mathrm{B})$.

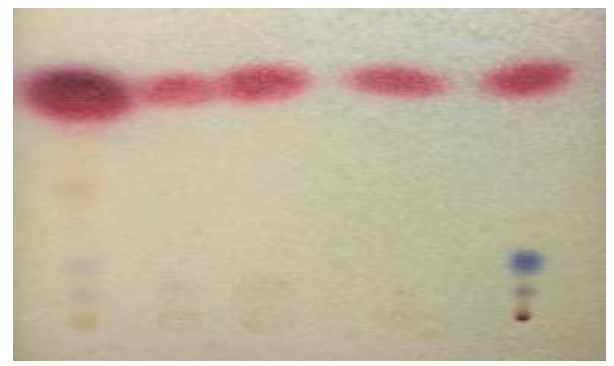

S P B

Fonte: Própria (2019)

As análises no infravermelho comprovam que ocorreu a biorredução do composto carbonilíco ao álcool correspondente. As Figuras 08-09 representam os espectros de IV obtidos para o composto 4 ( $\alpha$-tetralona) e seu bioproduto de biorredução. A partir da análise do espectro de infravermelho os compostos puderam ser caracterizados. No espectro IV do substrato 4 (Figura 08) verificamos a presença de banda de carbonila de cetona conjugada em $1.683 \mathrm{~cm}^{-1}$. Na Figura 09, espectro do bioproduto, constatamos que houve reação de biorredução, pois observamos uma banda em $3.418 \mathrm{~cm}^{-1}$ correspondente à hidroxila de álcool, o que nos sugere a formação do álcool 1-tetralol. Porém a reação não ocorreu totalmente, uma vez que verificamos no espectro do bioproduto a presença de banda em $1.680 \mathrm{~cm}^{-1}$ de carbonila de cetona conjugada.

Figura 08: Espectro de infravermelho do substrato 4 ( $\alpha$-tetralona)

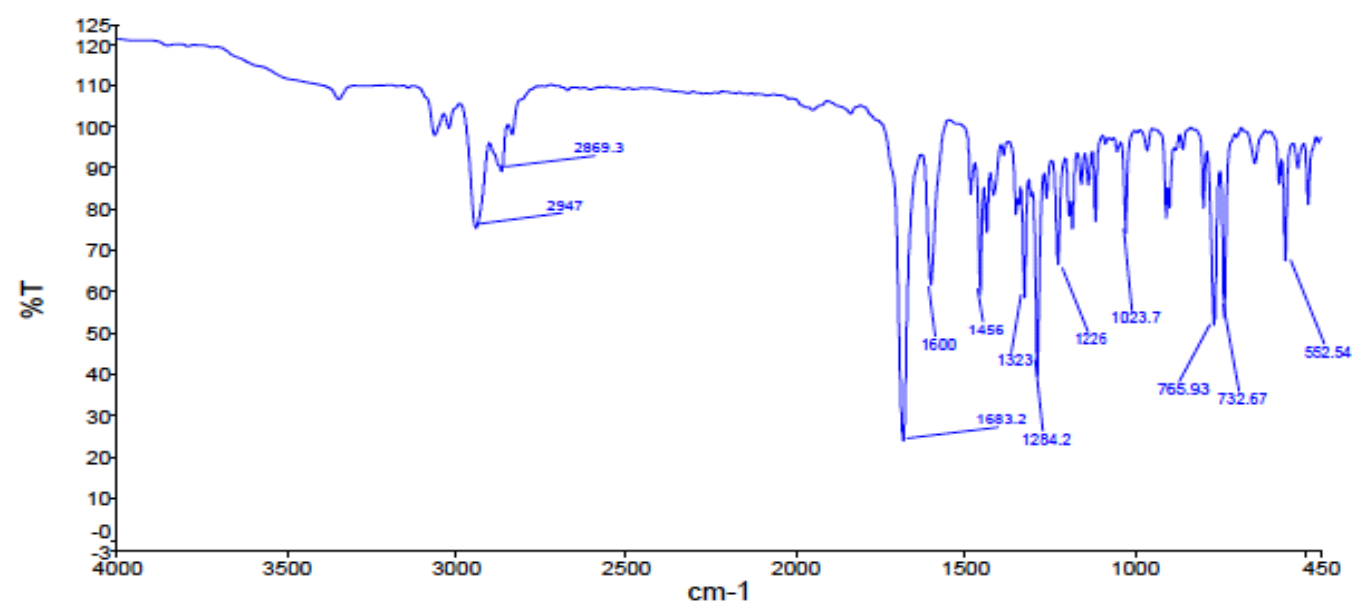


Fonte: espectroscopia no infravermelho - o(s) autor(es)

Figura 09: Espectro do bioproduto de biorredução da $\alpha$-tetralona, álcool 1-tetralol

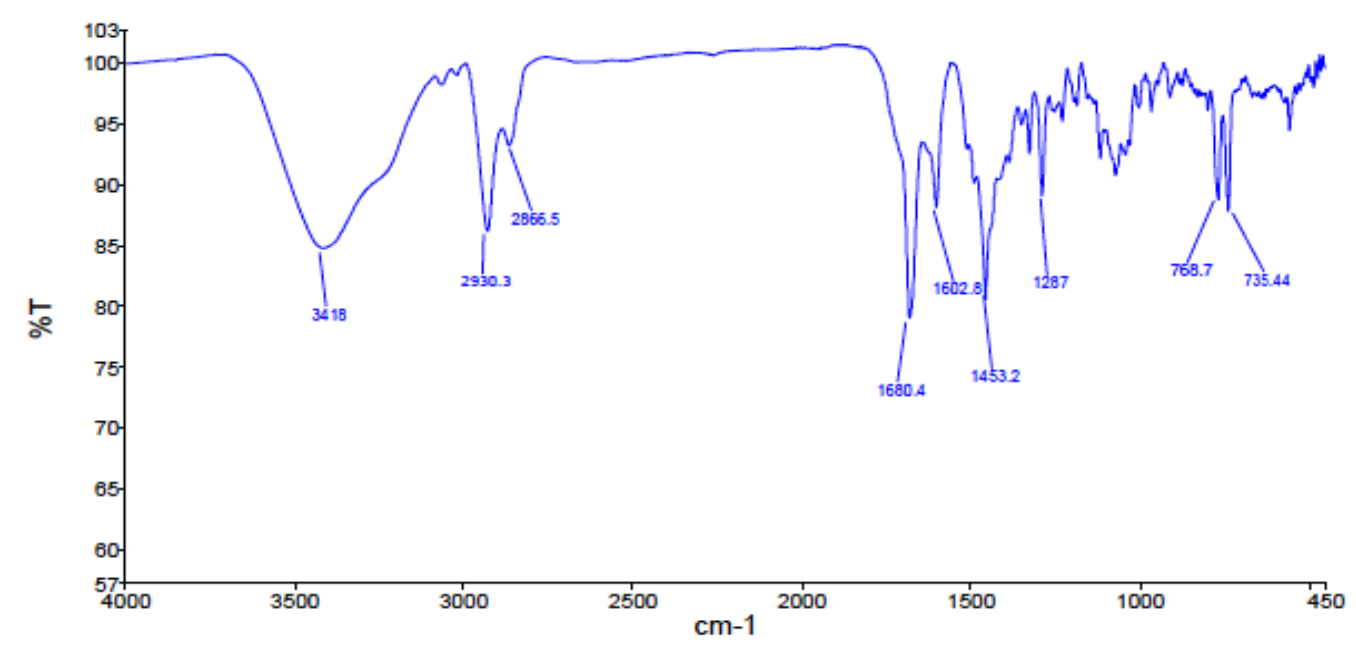

Fonte: espectroscopia no infravermelho - o(s) autor(es)

Determinação do teor de proteínas

Os teores de proteínas foram determinados segundo o método de Bradford, para o biocatalisador feijão-fava.

Os resultados abaixo mostram as respectivas absorbâncias obtidas para as concentrações da solução padrão (Tabela 01). Esses valores (média) foram plotados no gráfico para obtenção do $\mathrm{R}^{2}$. Com os valores de $\mathrm{R}^{2}$ da equação da reta obtida, foi possível determinar a concentração de proteínas provenientes nas amostras vegetais.

Tabela 01: Absorbâncias obtidas para as concentrações da solução padrão

\begin{tabular}{|c|r|r|r|r|}
\hline [ ] & g/mL & A1 & A2 & média \\
\hline 10 & & & & \\
\hline 20 & & 0,567 & 0,523 & 0,545 \\
\hline 30 & & 0,690 & 0,625 & 0,658 \\
\hline 40 & & 0,839 & 0,735 & 0,787 \\
\hline 50 & & 0,893 & 0,827 & 0,860 \\
\hline 60 & & 1,018 & 1,027 & 1,023 \\
\hline
\end{tabular}

Fonte: Própria (2019) 
Com estas absorbâncias foi possível obter uma curva de calibração sendo representada pela seguinte gráfico:

Figura 10: Gráfico da curva de calibração

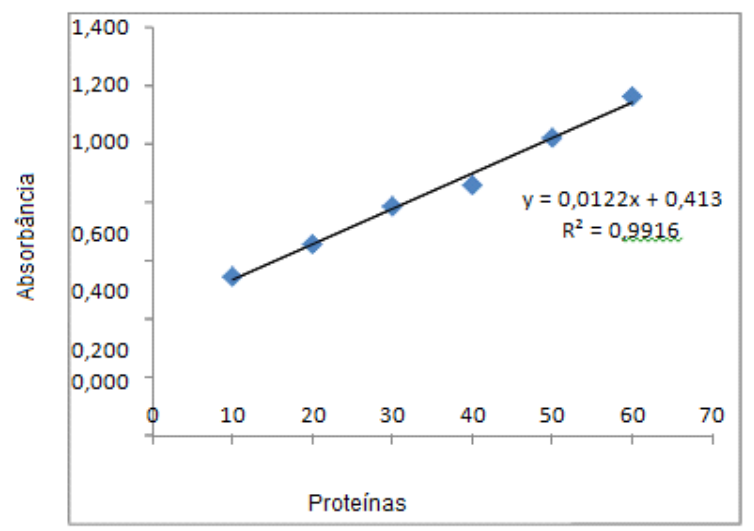

Fonte: Própria (2019)

Sabendo dos valores da média, as concentrações utilizadas e a curva padrão de Albumina bovina, o cálculo de proteína dos vegetais foi feito com a equação:

$$
\mathrm{Y}=0,0122 \mathrm{x}+0,413 \quad \mathrm{R}^{2}=0,9916
$$

Onde y = Absorbância; $\mathrm{x}=$ Concentração da amostra.

Os resultados das concentrações de proteínas totais do extrato de feijão-fava são apresentados na Tabela 02 .

Tabela 02: Concentração de proteínas segundo o método de Bradford no vegetal Phaseolus lunatus L.(feijãofava).

\begin{tabular}{|c|c|}
\hline Dados & Amostra feijão-fava \\
\hline & \\
\hline A1 & 1,208 \\
\hline A 2 & 1,194 \\
\hline C1 & 65,2 \\
\hline C2 & 64,0 \\
\hline Média & 64,6 \\
\hline $\mathrm{C} 1 * 50 \mathrm{x} \mu \mathrm{g} / \mathrm{mL}$ & 3258,2 \\
\hline $\mathrm{C} 2 * 50 \mathrm{x} \mu \mathrm{g} / \mathrm{mL}$ & 3200,8 \\
\hline Média & 3229,5 \\
\hline Desvio & 40,6 \\
\hline
\end{tabular}


A= Absorbância; $C=$ Concentração.

$\mathrm{O}$ valor proteico encontrado para o extrato de feijão-fava indica que esse vegetal pode ser utilizado com potencialidade em reações de biocatálise, apresentando-se como um promissor biocatalisador.

\section{Conclusões}

Os resultados obtidos a partir das biotransformações de cetonas utilizando o feijãofava como biocatalisador, revelam a presença de enzimas redutases como responsáveis pelas biorreduções observadas. Pode-se perceber isso através da análise de CCD e dos espectros de infravermelho dos bioprodutos, a presença de banda característica de hidroxila de álcool indicando que a ocorreu reação para todos os substratos: acetonaftona, 2,4dicloroacetofenona, 2-octanona e alfa-tetralona. Dessa forma, podemos afirmar que o feijãofava atua como biocatalisador promissor em reações de biorredução, de forma que há muito que se investigar tanto nesse vegetal quanto em outros, buscando através da biotecnologia, bioprodutos com mais aplicabilidade no setor industrial/sintético.

\section{Referências}

ANDRADE, L. H. et al. Edible catalysts for clean chemical reactions: Bioreduction of aromatic ketones and biooxidation of secondary alcohols using plants. Journal of Molecular Catalysis B- Enzymatic, v.38, n.2, p.84-90, 2006.

BIZERRA, A. M. C. et al. Reduction processes biocatalyzed by Vigna unguiculata. Tetrahedron-Asymmetry, v.21, n.5, p.566-570, 2010.

BRADFORD, M. M. A. Rapid and Sensitive Method for the Quantitation of Microgram Quantities of Protein Utilizing the Principle of Protein-Dye Binding. Analytical Biochemistry, v.72, p.248-254, 1976.

CONTI, R.; RODRIGUES, J. A. R.; MORAN, P. J. S. Biocatálise: avanços recentes. Química Nova, v.24, n.5, p.672-675, 2001.

GIRI, A. et al. Biotransformations using plant cells, organ cultures and enzyme systems: current trends and future prospects. Biotechnology Advances, v.19, n.3, p.175-199, 2001. 
HARTREE, E. F. Determination of protein a modification of the Lowry Method that gives a linear photometric response. Analytical Biochemistry, v.48, p.422-427, 1972.

ISHIHARA, K. et al. Biotransformation using plant cultured cells. Journal of Molecular Catalysis B-Enzymatic, v.23, n.2-6, p.145-170, 2003.

LIMA, A. W. O.; ANGNES, L. Biocatálise em meios aquo-restritos: fundamentos e aplicações em química analítica. Química Nova, v.22, p.229-245, 1999.

MACHADO, L. L. et al. Enantioselective acetylation of racemic alcohols by Manihot esculenta and Passiflora edulis preparations. Journal of Molecular Catalysis B-Enzymatic, v.60, n.3-4, p.157-162, 2009.

MACHADO, L. L.; SOUZA, J. S. N.; MATTOS, M. C.; SAKATA, S. K.; CORDELL, G. A.; LEMOS, T. L. G. Bioreduction of Aldehydes and Ketones using Manihot species. Phytochemistry, v.67, p.1637-1643, 2006.

MORAES, M. I. Biorredução de aldeídos e cetonas utilizando células íntegras de espécies vegetais cultivadas no Estado do Piauí. 2014. Dissertação (Mestrado em Química Orgânica)- Universidade Federal do Piauí, Edições UFPI, Teresina, Brasil, 2014.

OMORI, A. T.; PORTAS, V. B.; DE OLIVEIRA, C. D. Enzymatic reduction of 4dimethylamino)benzaldehyde with carrot bits (Daucus carota): a simple experiment for understading biocatalysis. Química Nova, v.35, n.2, p.435-437, 2012.

ORDEN, A. A. et al. Anti-Prelog reduction of ketones by hairy root cultures. Journal of Molecular Catalysis B-Enzymatic, v.61, n.3-4, p.216-220, 2009.

VIEIRA, E.C.; GAZZINELLI, G.; MARES-GUIA, M. Bioquímica celular e biologia molecular. $2^{\circ}$ ed. Atheneu,1996. 